\title{
Case Report of Pregnancy with Huge Fibroid
}

\section{Hemali Bharat Karia, MBBS, DGO ${ }^{1 *}$, Deepa Maniar, MBBS, $M D^{2}$ and Ketan Gosai, $M B B S, M D^{3}$}

${ }^{1}$ Assisstant Gynecologist, Mangalam Maternity Home and Surgical Hospital, Rajkot, Gujarat, India

${ }^{2}$ Chief Gynecologist, Mangalam Maternity Home and Surgical Hospital, Rajkot, Gujarat, India

${ }^{3}$ Associate Professor, PDU Medical College, Rajkot, Gujarat, India

*Corresponding author: Dr. Hemali Bharat Karia, MBBS, DGO, Assisstant Gynecologist, Mangalam Maternity Home and Surgical Hospital, Rajkot, Gujarat

\section{Introduction}

- Uterine fibroids are benign smooth muscle tumours of the uterus.

- Its prevalence during pregnancy has been reported to be $1-4 \%[1]$.

- Pregnancy along with a fibroid is a high risk pregnancy which may lead to complication with unequal gravity.

- Their presence has been linked to spontaneous abortion, intrauterine growth restriction (IUGR), anemia, multiple blood transfusions, infection, pain, degeneration, malposition of foetus, premature labour, uterine inertia, placental abruption, postpartum hemorrhage, retention of the placenta, increased rates of cesarean section, hysterotomy, obstetric hysterectomy [2-6].

\section{Case Presentation}

- We present a case report of a patient with pregnancy with multilobulated fibroid (subserosal) (broadbased, not pedunculated) occupying whole lower uterine segment.

- Details of patient and challenges faced -

Age - 30 years

Obstetric history - Married since 1 and half years; Spontaneous Conception

\section{Case History}

- Patient was diagnosed fibroid with pregnancy at 8 weeks of gestation with MRI suggestive of huge subserosal multilobulated fibroid arising from anterior wall of uterus extending in abdomen up to epigastric region, total mass measuring $10 \times 19 \times 23 \mathrm{~cm}$ with areas of degeneration (cystic).

- Anteriorly, it reaches up to anterior abdominal wall, postero-superiorly pressing over retroperitoneum causing mass effect over aorta \& IVC postero-inferiorly causing mass effect over endometrial cavity, inferiorly causing mass effect over urinary bladder.

- At her town place, primarily she was advised termination. She was also explained regarding need of myomectomy after MTP and SOS chances of hystrectomy. But she wanted to continue the pregnancy.

- She presented to us at 22 weeks of gestation after anomaly scan, which was normal, with maternal weight $34 \mathrm{~kg}$.

- Routine obstetric care given.

- Patient presented with pain in abdomen at 24 weeks of gestation. USG done and was found normal. Size of multilobulated fibroid being $13 \mathrm{~cm}$ and $10 \mathrm{~cm}$ respectively, extending into lower uterine segment.

- Complete blood count and CRP done which was suggestive of infection. Conservative management with IV antibiotics. We counselled her regarding need of conservative management till viable age of fetus.

- After 3 weeks (at 27 weeks), patient was posted for cesarean section due to persistent complaint of pain in abdomen and discomfort.

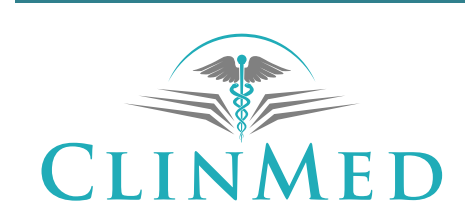

INTERNATIONAL LIBRARY

Citation: Karia HB, Maniar D, Gosai K (2021) Case Report of Pregnancy with Huge Fibroid. Obstet Gynecol Cases Rev 8:189. doi.org/10.23937/2377-9004/1410189

Accepted: January 19, 2021: Published: January 21, 2021

Copyright: (C) 2021 Karia HB, et al. This is an open-access article distributed under the terms of the Creative Commons Attribution License, which permits unrestricted use, distribution, and reproduction in any medium, provided the original author and source are credited. 


\section{Pre Operatively}

- 2 units of blood transfused.

- A high risk informed consent with arrangement of multiple blood products and SOS chances of cesarean hystrectomy, chances of ICU admission and fetal risk were explained.

- MRI done which showed mass of $14.5 \times 12.8 \times 24$ $\mathrm{cm}$ arising from anterior wall of uterus, displacing it to right half of abdomen, extending in abdomen up to epigastric region, inferiorly displacing the urinary bladder.

\section{Intra-Operative Events and Management}

- Under spinal anesthesia, right para-median vertical skin incision was given. Mass was multilobulated occupying entire anterior surface of the uterus.

- Manipulation of the mass was done in order to find the space for the incision.

- Entire anterior surface of the uterus was occupied by the mass except a long 4-5 cm strip like area on right lateral wall just below the round ligament.

- Vertical incision was taken on the mass free area.

- As the cavity was not reached, finger was inserted, amniotic sac palpated and ruptured with long artery forceps.

- Baby delivered with the help of fundal pressure. (Weight of the baby $-1.1 \mathrm{~kg}$ ). Baby cried immediately after birth.

- Bilateral uterine artery ligation done.

- Myomectomy done. Fibroid of $2.4 \mathrm{~kg}$ removed.

- 2 units of blood transfused.

- Hemorrhage was within manageable limits and a cesarean hystrectomy was avoided.

- Baby was on ventillator after birth, weaned off on day 8 of life and was continued on RT feed.

\section{Post Operative Period}

- She had an uneventful post-op recovery.

- The histopathology of fibroid showed hyaline degeneration without mitotic figures.

- Barrier method was advised strictly for 3 years (Figure 1, Figure 2 and Figure 3).

\section{Discussion}

- The relationship of fibroids and adverse outcomes in pregnancy are not clearly understood [7].

- Mostly the fibroids are asymptomatic with only $9 \%$ of large fibroids showing any symptoms; mainly lower abdominal pain in the $2^{\text {nd }}$ or $3^{\text {rd }}$ trimester $\mathrm{s}$ suggestive of red degeneration.

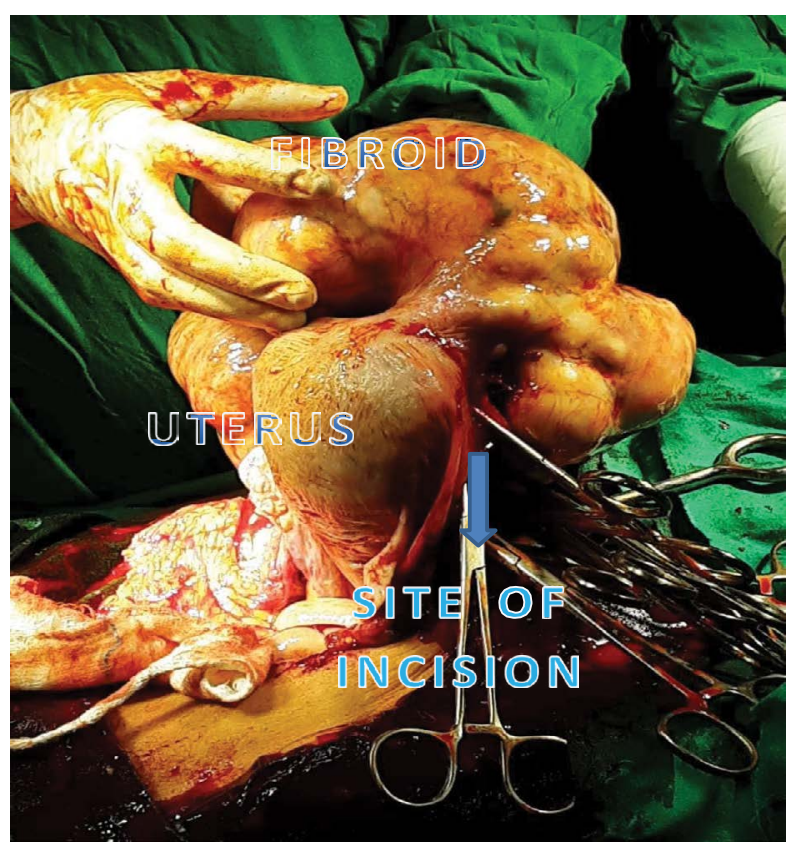

Figure 1: Uterus with fibroid after delivery of baby vertical uterine incision taken.

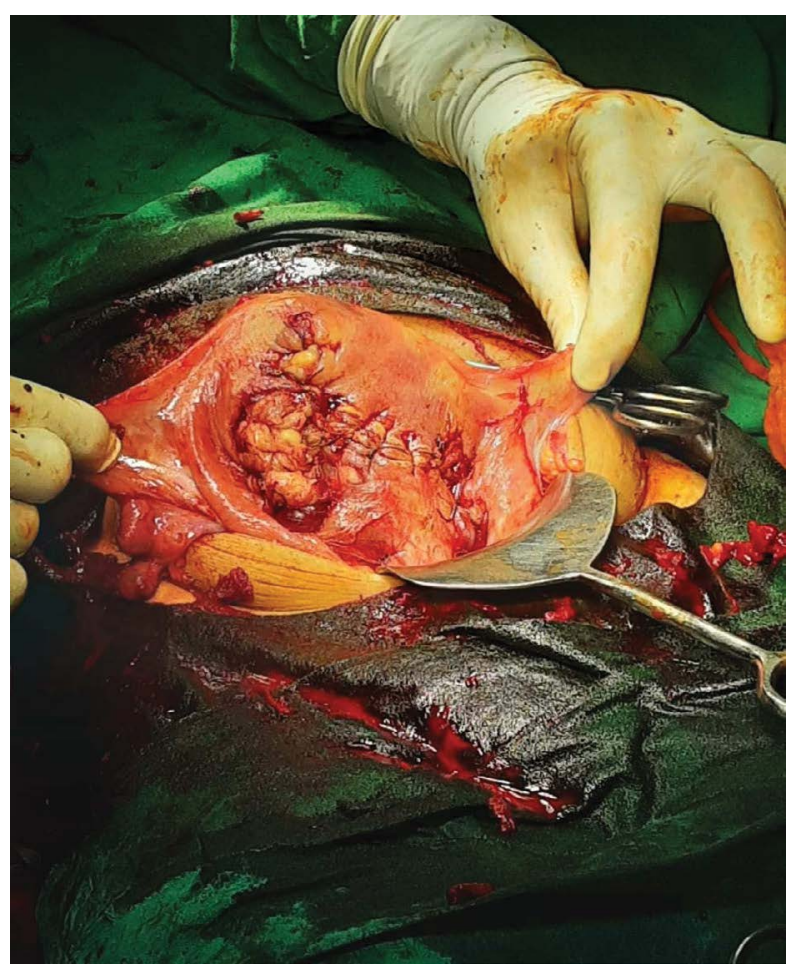

Figure 2: Uterus after myomectomy and bilateral uterine ligation.

- Vice versa around $10-30 \%$ fibroids have complications in pregnancy [8].

- Early miscarriages are more common with multiple fibroids $[9,10]$.

- The risk of preterm labour is significantly increased with both multiple fibroids and with large fibroids (> $5 \mathrm{~cm}$ ) [11].

- Multiple fibroids especially lower uterine segment increase chances of cesarean section [12,13]. 


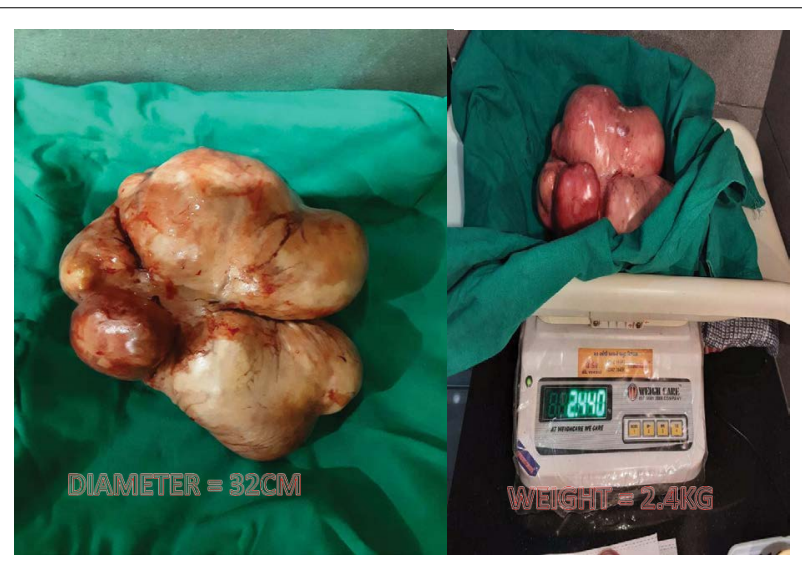

Figure 3: Fibroid with diameter and weight.

- Blood loss at delivery is increased for fibroids $>5 \mathrm{~cm}$.

- Myomectomy at the time of cesarean delivery causes severe hemorrhage and should be reserved only for subserous, pedunculated fibroids. However cesarean myomectomy with fibroids $>5 \mathrm{~cm}$ size in experienced hands in tertiary care centres with stepwise de-vascularisation has been found relatively safe [14-17].

\section{Conclusion}

- In this case, patient was unaware of fibroid before conception. It turned out to be a wise decision to continue her pregnancy as we were able to wait till weight of the baby reached $1 \mathrm{~kg}$.

- Dilemmas in decision making-

1. Whether to continue pregnancy or to terminate the pregnancy and to do interval myomectomy pre-conception.

2. Whether to go for cesarean myomectomy or not. Subserosal, especially pedunculated, are definitely to be removed. For intramural fibroids, decision depends on surgical skill, location of the fibroid, size of the fibroid, availability of the infrastructure, blood and blood products, expert assisstants and intensive care.

\section{Key Points Regarding Management in this Case}

1. Proper counselling of the patient and her relatives.

2. Co-operation on patient's side.

3. Dedicated team of gynecologist + physician + paediatrician + anesthetist.

4. Availability of blood and blood products.

5. Post operative care.

6. NICU care.

7. Strict contraception by barrier method in order to maintain adequate spacing and prevention of rupture of scar and uterus.

\section{References}

1. Buttram VC, Reiter RC (1981) Uterine leiomyomata: Etiology, symptomatology and management. Fertil Steril 36: 433-445.

2. Ciavattini A, Clemente N, Delli Carpini G, Jacopo Di G, Stefano Raffaele G, et al. (2015) Number and size of uterine fibroids and obstetric outcomes. J Matern Fetal Neonatal Med 28: 484.

3. Coronado GD, Marshall LM, Schwartz SM (2000) Complications in pregnancy, labor, and delivery with uterine leiomyomas: A population-based study. Obstet Gynecol 95: 764.

4. Dogan S, Ozyuncu O, Atak Z (2016) Fibroids during pregnancy: Effects on pregnancy and neonatal outcomes. J Reprod Med 61: 52.

5. Jenabi E, Khazaei S (2018) The effect of uterine leiomyoma on the risk of malpresentation and cesarean: A meta-analysis. J Matern Fetal Neonatal Med 31: 87.

6. Lam SJ, Best S, Kumar S (2014) The impact of fibroid characteristics on pregnancy outcome. Am J Obstet Gynecol.

7. Qidwai II, Caughey AB, Jacoby AF (2006) Obstetric outcomes in women with sonographically identified uterine leiomyomata. Obstet Gynecol.

8. Gupta S, Jose J, Manyonda I (2008) Clinical presentation of fibroids. Best Pract Res Clin Obstet Gynaecol 22: 615-626.

9. Salvador E, Bienstock J, Blakemore KJ, Eva Pressman (2002) Leiomyomata uteri, genetic amniocentesis, and the risk of second trimester spontaneous Abortion. Am J Obstet Gynecol 186: 913.

10. Stout MJ, Odibo AO, Graseck AS, George A Macones, James P Crane, et al. (2010) Leiomyomas at routine Second-trimester ultrasound examination and adverse obstetric outcomes. Obstet Gynecol.

11. Klatsky PC, Tran ND, Caughey AB, Fujimoto VY (2008) Fibroids and reproductive outcomes: A systematic literature review from conception to delivery. Am J Obstet Gynecol 198: 357-366.

12. Neiger R, Sonek JD, Croom CS, Ventolini G (2006) Pregnancy-related changes in the size of uterine leiomyomas. $J$ Reprod Med 51: 671-674.

13. Casini ML, Rossi F, Agostini R, Unfer V (2002) Effects of the position of fibroids on fertility. Gynecol Endocrinol 22: 106-109.

14. American College of Obstetricians and Gynecologists (2008) ACOG practice bulletin. Alternatives to hystrectomy in the management of leiomyomas. Obstet Gynecol.

15. Celik C, Acar A, Cicek N, Kazim Gezginc, Cemalettin Akyurek (2002) Can myomectomy be performed during pregnancy? Gynecol Obstet Invest 53: 79.

16. De Carolis S, Fatigante G, Ferrazzani S, C Trivellini, L De Santis, et al. (2011) Uterine myomectomy in pregnant women. Fetal Diagn Ther 11: 739.

17. Lefebvre G, Vilos G, Allaire C, Nicholas Leyland (2003) The management of uterine leiomyomas. J Obstet Gynaecol Can 25: 396-418.
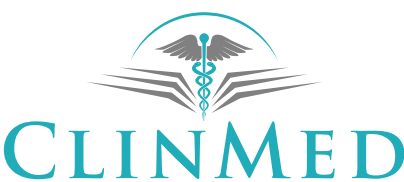

INTERNATIONAL LIBRARY 